\title{
Ediciones de las tradiciones de Palma
}

\author{
Alberto Varillas Montenegro \\ Academia Peruana de la Lengua \\ Instituto Riva Agüero \\ varillas.alberto@gmail.com
}

\section{Resumen}

Ricardo Palma no solo es uno de los más importantes escritores peruanos sino que sus Tradiciones peruanas son una de las obras nacionales más editadas. En los últimos 130 años han aparecido ediciones que se proclaman clásicas o críticas de las Tradiciones peruanas completas: aquí se pretende ponderar el rigor de dichas ediciones desde la perspectiva tanto de la crítica como de la de los lectores.

Palabras clave: Palma, Tradiciones peruanas completas, ediciones.

\section{Abstract}

Ricardo Palma is not only one of the most important Peruvian writers but his Tradiciones peruanas is one of the most edited works of the Peruvian literature. During the last 130 years, editions of the Tradiciones peruanas have been published as classic or critical editions. In this paper we try to evaluate their quality from the standpoint of the academic and the popular reader.

Keywords: Palma, Tradiciones peruanas completas, editions. 
Alberto Varillas Montenegro, Miembro de número de la Academia Peruana de la Lengua, la Academia Nacional de la Historia, el Instituto Riva Agüero y el Instituto Ricardo Palma. Se ha especializado en la historia y la literatura del Perú del siglo xix. Entre otras obras ha publicado Felipe Pardo y Aliaga, La literatura del Perú del siglo xix, Perú y Ecuador. Visión actual de un antiguo conflicto, Periodismo e historia del Perú en el siglo xix, Apuntes para una historiografía de la literatura peruana del siglo xix. Ha editado las Obras completas de Manuel A. Segura. 
Resulta una osadía ocuparme de las ediciones de las Tradiciones Peruanas de Ricardo Palma ante un grupo de palmistas. Más aún, hacerlo después de que Cecilia Moreano y Julio Díaz Falconí prepararan importantes bibliografía y cronología de las mismas, respectivamente, hace ya un buen número de años. Sin embargo, conviene ponderar, de tiempo en tiempo, el verdadero valor que ellas tienen.

Quizás los comentarios que siguen están preparados más para quienes se deleitan con la lectura las Tradiciones que para investigadores de la obra de Palma, pero, quizás, ese es el espíritu de estas Jornadas de Re-visión de las Tradiciones Peruanas.

En esta presentación no quiero ocuparme del origen de las Tradiciones sino de sus ediciones más importantes, comenzando por la que el propio tradicionista iniciara en 1872 hasta la más reciente, la de la Universidad Ricardo Palma, con edición, prólogo y notas de Miguel Ángel Rodríguez Rea.

Hacia 1870, el más importante de los escritores peruanos en el ejercicio de la profesión era Ricardo Palma. Secretario particular del presidente Balta y senador por Loreto, había desistido de sus fracasadas pretensiones juveniles como autor dramático (cuatro obras más algunas escenas de El santo de Panchita), había publicado tres poemarios (Poesías, Lima, 1855; Armonías, París, 1865 y Pasionarias, Havre, 1870) y distintas publicaciones periódicas limeñas y del extranjero habían recogido ya una treintena de sus tradiciones.

\section{Primera edición}

En ese momento, don Ricardo opta por editar la primera recopilación de sus tradiciones: 18 textos de los cuales 3 eran 
inéditos más sus Anales de la Inquisición de Lima. Conocido es el hecho de que casi hasta el momento de llevar el material a la imprenta, Palma aún no había decidido el título del libro que finalmente fue simplemente Tradiciones. ${ }^{1}$ El tiraje fue de 500 ejemplares que pareciera que fueron adquiridos rápidamente, lo que motivo al autor, mientras continuaba publicando tradiciones nuevas, a tratar de completar la primera edición y lo hace publicando otros tres volúmenes en los años 1874, 1875 y 1877.

Sin embargo, según ha investigado Díaz Falconí (2015: 50-52), resulta que esta edición en cuatro volúmenes era susceptible de ser completada si nos atenemos a que con fecha 14 de mayo de 1878 Palma remite a Madrid 45 tradiciones adicionales para las cuales aparentemente no había conseguido impresor limeño que le conviniera. Hasta la fecha no existe información adicional sobre esta frustrada edición madrileña; sin embargo, se conoce la relación-aunque no los textos- de las 45 tradiciones enviadas. La mayor parte de estas tradiciones fueron incorporadas como quinta y sexta serie a partir de la edición de $1883^{2}$.

Esta es, pues, la primera edición de las Tradiciones. Bastante incompleta, como es posible comprobar, además de materia de múltiples correcciones incorporadas por el propio Palma, escritor que nunca estuvo satisfecho de sus obras sino que les alteró los títulos e incorporó a ellas modificaciones de distinta importancia.

l En efecto, en carta de 26 de marzo de 1872 le anuncia a su amigo argentino Juan María Gutiérrez que en junio comenzará la impresión de un libro que estará compuesto de Veinte tradiciones o leyendas peruanas [sic] cuyo mérito es narrar acontecimientos de nuestra historia colonial. Fueron 18 y no veinte.

2 Cecilia Moreano en su Bibliografía de Ricardo Palma, estudia en forma muy minuciosa la forma en que las cuatro series de la década de 1870 pasan a ser seis en la edición de 1883 . 


\section{Segunda edición}

La segunda edición de Tradiciones (Lima, Imprenta del Universo de Carlos Prince, 1883) aparece en seis volúmenes y nos presenta un corpus bastante ordenado. Cada uno de los volúmenes está precedido de diferente material a guisa de prólogo. En uno de éstos, el impresor francés Prince que ya llevaba asentado en Lima diez años, recuerda que había recibido los originales a fines de 1880 y que eso determinó que se salvaran durante la Guerra del Pacífico, cuando en enero de 1881 las tropas chilenas destruyen la ciudad de Miraflores e incendian el domicilio del tradicionista. De acuerdo con las fechas de los distintos prólogos, la edición debe haber aparecido a fines de 1883 pues, según refiere el jefe de la ocupación contralmirante Lynch en la segunda Memoria que presenta al gobierno de Chile, desde el 21 de abril de 1882 quedó prohibido en el Perú “... la publicación de libros, folletos, hojas sueltas y cualquier otra clase de impresos" sin aprobación previa ${ }^{3}$.

Esta edición de las Tradiciones es muy meritoria si se considera que Lima llevaba más de dos años de torpe ocupación militar y que la situación económica era dramática dada la reiterada imposición de cupos que se obligaba en forma indiscriminada a la población. Sin embargo, Palma no deja la oportunidad de hacer presente su decepción y a alguno de sus corresponsales le manifiesta que Prince también era consciente de ello y que en su Prólogo reconoce que ésta era una edición económica.

Pero seguramente no se imaginó el descontento que ella le causaría al propio Palma, quien así se lo hace saber tiempo después a su amigo el escritor mexicano Vicente Riva Palacio:

3 Resolución de 21 de abril de 1882. En: Patricio Lynch, Segunda Memoria que el Contra Almirante D. Patricio Lynch, Jeneral en Jefe del Ejército de operaciones en el norte del Perú presenta al Supremo Gobierno de Chile.Lima. Imp. de la Merced, Peter Bacigalupi y Ca., 1883. Pág. x 
"La edición es tan pobre que peca de vergonzante. [...] Edición popular o económica, carece de belleza tipográfica, con no poco sufrimiento para mi amor de padre."4 Pese a su limitada calidad, esta edición es de fundamental importancia para el estudio de Palma y sus tradiciones pues se trata de la primera colección preparada en forma personal por el autor y, sin la menor duda, publicada bajo su supervisión. ${ }^{5}$

\section{Tercera edición}

La tercera edición de las Tradiciones la negoció Palma personalmente en Barcelona con los editores Montaner y Simón a principios de 1893. Esta fue la última edición completa de Tradiciones que se publica en vida de Palma y la primera que lleva como título Tradiciones peruanas. Fue, además, la utilizada por el gobierno peruano para la edición de homenaje al tradicionista que auspició en 1923 o 1924.

Las conversaciones entre autor y editores no deben haber sido del todo satisfactorias pues los catalanes, con una visión comercial mejor desarrollada, no estuvieron de acuerdo con publicar la totalidad de los textos remitidos por Palma. No se sabe cuántos ni menos cuáles fueron las tradiciones separadas pero con ellas publicó Palma en Lima, años más tarde (1899), el volumen titulado Tradiciones y artículos históricos en que las reúne junto con otras preparadas en los últimos cinco años.

Durante mucho tiempo, esta fue la edición consultada con mayor frecuencia por los estudiosos de Palma para comentar las Tradiciones, aunque luego fueron preferidas las de Cultura Antártica y ALLCAXX/Fondo de Cultura Económica.

4 Ver mi estudio preliminar a El Demonio de los Andes, pág. xlix.

5 No cabe mencionar relación completa de las Tradiciones puesto que "Ropa vieja y Ropa apolillada” aparecen en 1889 y 1891 , respectivamente. 
Esta edición fue repetida en 1911 en Callao por A. J. Segrestán con dos errores, que en su momento observó Raúl Porras Barrenechea: se le tituló ...Tradiciones selectas, pese a que reproduce fielmente la edición barcelonesa, y se le subtituló ... edición corregida, cuando se limitó a reproducir la de 1893.

\section{Cuarta edición}

Una buena edición fue la que en 1923 o 1924 apareció en Madrid, por la editorial Calpe, auspiciada por el gobierno peruano. Se trata de cinco volúmenes, que repiten el orden de la edición de Montaner y Simón de 1893 pero que añade las publicadas por Palma en 1910 como Mis últimas tradiciones peruanas y Cachivachería y un sexto volumen con las tradiciones que habían aparecido en el Apéndice a mis últimas tradiciones peruanas publicado por la editorial Maucchi, también en Barcelona, en 1910.

La edición estuvo a cargo de Angélica Palma, escritora y periodista, la mayor de las hijas de don Ricardo, quien actuó asistida por sus hermanas Renée y Augusta. La edición tiene el mérito de ser la última en que se respeta el orden establecido por Palma para la de 1893.

\section{Quinta edición}

Más de 25 años después, en 1951 aparece en Lima la edición de la Editorial Cultura Antártica, en 6 volúmenes, que viene precedida por una valiosa bibliografía preparada y comentada extensamente por Raúl Porras Barrenechea (80 págs.).

Esta edición, que sigue a la buena edición de Calpe (1923/24), fue la primera preparada con seriedad en el Perú, pero tuvo una vida efímera pues fue reemplazada como texto de lectura 
y consulta por la que preparara dos años más tarde la Editorial Aguilar. Fue reeditada por la Librería Internacional en 1959.

\section{Sexta edición}

La edición más exitosa de las Tradiciones peruanas ha sido hasta hoy, sin duda, la de Aguilar, s. a. de Ediciones (Madrid, 1953), que ha sido reeditada en numerosas ocasiones. Como editora y prologuista figura Edith Palma, nieta de don Ricardo en su condición de hija de Clemente Palma, el mayor de los vástagos del tradicionista.

La edición en sí resulta valiosa pues reúne en 1200 páginas todas las Tradiciones Peruanas conocidas hasta entonces (luego se ha descubierto otra) y en otras 600 páginas los Anales de la Inquisición, ensayos como La Bohemia de mi Tiempo y Recuerdos de España, artículos y epístolas, un sinnúmero de índices, etc.

La edición se presenta como "Edición clásica", término que no sabemos muy bien qué significa, pero estimamos que en ella se comete un error al tratar de seguir un orden cronológico e histórico de las tradiciones. La decisión de optar por ese orden obligó a los editores a reunir en unas cuantas páginas las dedicadas a la época incaica junto con la conquista, en contraposición a las de temática virreinal o republicana, y a verse obligados a ubicar entre las ambientadas durante los años de dominio español a las correspondientes a los períodos de dominio de la Casa de Austria y de los Borbones. Discrepa también con esta decisión Julio Ortega, uno de los editores de la primera edición crítica de las Tradiciones. 


\section{Sétima edición}

La siguiente edición de las Tradiciones peruanas es la de Julio Ortega y Flor María Rodríguez-Arenas (ALLCAXX/Fondo de Cultura Económica). Esta edición revela un considerable esfuerzo editorial pero no ofrece una colección completa de las Tradiciones sino que selecciona entre ellas. Ortega lo indica con cuidado en su prólogo:

...se seleccionan en este volumen las "tradiciones" que mejor representan el repertorio de intereses, temas y estilos del autor así como se cubren todas sus etapas, serializadas por él mismo. Dado que una selección implica una valoración, se ha preferido partir no solo del juicio propio sino del consenso crítico establecido. Para ello, se han cotejado las antologías más conocidas, desde la de Ventura García Calderón (1938) hasta la de José Miguel Oviedo (1977), y se han añadido algunas piezas que completan el escenario de la "tradición". Así, esta selección es más que una antología: se basa en el consenso de lectura pero no para repetirlo sino para cotejarlo, seleccionar dentro del mismo, y completarlo. Confiamos que este libro promueva una relectura más fresca y más pertinente de estas "tradiciones" que, en sí mismas, están reñidas con cualquier monumentalidad canónica. (Ortega, 1996: xxvii-xxviii)

De esta edición se nos presentan una duda y una observación. La duda: no creemos que convenga preparar una edición crítica, tal como se anuncia en la portada de la edición, a base de una antología pues los criterios de selección de materiales de García Calderón y Oviedo distan entre sí 40 años. La observación: preparar una edición crítica de las Tradiciones peruanas que a lo largo de más de medio siglo se publicaron en forma de libro o fueron recogidas en revistas y periódicos de tantos países resulta una labor homérica. 
Y para muestra un botón: señalan Ortega y Rodríguez-Arenas que en Los tres motivos del oidor, tradición publicada dentro de la primera edición de El Demonio de Los Andes (Nueva York, 1883), aparecía el siguiente texto que posteriormente fue eliminado: "Añada usted que la chica no leía otros libros que Vidas de santos que, tengo para mí, son las más pecaminosas de las lecturas. Vidas hay escritas que más que a la literatura mística, pertenecen a la literatura de burdel."

Lo cual es correcto, pero omiten señalar otra discrepancia de textos aparecida en la página siguiente:

En la primera versión de Los tres motivos del oidor, el final del penúltimo párrafo de la segunda parte de la tradición reza así: “...Lo que yo tengo que hacer es casarte.... Y te casaré como hay viñas en Jerez”; en las ediciones de Nueva York (1883), Prince (1883) y Montaner y Simón (1894) aparece un añadido: “... y entre tú y la Teresa [os] multiplicareis hasta que se gaste la pizarra”. Curiosamente, en la edición de Maucci (1911) aparece un añadido adicional: “. . o se rompa el lápiz”. (Varillas, 2016: lix-lx)

Evidentemente se trata de un gazapo. Por eso, indicábamos antes que pretender preparar una edición crítica de las Tradiciones peruanas era una tarea homérica.

\section{La primera edición crítica}

En esta presentación nos hemos referido únicamente a las colecciones completas -si así se les puede calificar- de las Tradiciones Peruanas. Sin embargo, cabe hacer una excepción puesto que no es posible dejar de referirse a la edición crítica emprendida por Pedro Díaz Ortiz. 
En el 2008, Díaz Ortiz emprendió la tarea de preparar una verdadera edición crítica de las Tradiciones Peruanas. En ese año apareció la de la Primera Serie, conformada por un extenso prólogo descriptivo, un cuadro titulado Evolución de la Primera Serie de las Tradiciones Peruanas, los prólogos de las ediciones de 1872, 1883 y 1893 y la edición propiamente dicha (en la que señala diversos errores en que han incurrido editores anteriores de esta primera serie). El texto se completa con una Adenda, que contiene las cuatro versiones distintas de Don Dimas de la Tijereta y la primera versión de siete de las tradiciones recogidas. Por supuesto, la obra concluye con la bibliografía y los índices correspondientes.

El trabajo de Díaz Ortiz es sumamente meritorio y estas palabras sirvan para animarlo a continuar con la publicación de esta obra, cuyo segundo volumen aparentemente ya se encuentra listo.

\section{La edición más reciente}

La última edición completa de las Tradiciones Peruanas la debemos a la Universidad Ricardo Palma que hoy nos congrega, comprende nueve volúmenes y se encuentra a cargo de Miguel Ángel Rodríguez Rea.

Los primeros 6 volúmenes presentan las once series de tradiciones y concluyen con las Tradiciones en salsa verde; el volumen $7^{\circ}$ es una recopilación realizada por Julio Díaz Falconí y está titulado Tradiciones olvidadas; el $8^{\circ}$ es una cronología de las tradiciones, preparada también por Díaz Falconí (que viene a ser una tercera edición, pues la primera apareció por partes en la Revista de la Casa Museo Ricardo Palma y la segunda en el año 2005). El noveno y último volumen está conformado por un Glosario de las Tradiciones peruanas preparado por 
Augusto Alcocer Martínez y completa esta obra memorable la bibliohemerografía y los índices onomástico y toponímico preparados por el propio doctor Rodríguez Rea, y no queremos ni pensar en cuantos nombres habrá insertado.

Creo que la mejor forma de completar esta relación, que en momentos puede ser algo tediosa, es describiendo someramente esta edición de la obra de Palma, a la cual deben añadirse los tres volúmenes del epistolario del tradicionista.

$\circ \circ \circ$

Todos los años nos reunimos los interesados en Ricardo Palma para recordar, de una forma u otra, la especial jerarquía de su obra que se concentra en las Tradiciones peruanas. Por eso, debemos agradecer al Instituto Ricardo Palma por la oportunidad que nos brinda para disfrutar, ocupándonos de la vida y la obra de un peruano ilustre, cuyo fallecimiento centenario recordaremos dentro de unos cuantos meses. 


\section{Bibliografía}

Díaz Falconí, J. (2015) Cronología de las Tradiciones Peruanas. Tercera edición aumentada y corregida. Lima: Facultad de Lenguas Moderna de la Universidad Ricardo Palma.

Moreano, C. (2001) Bibliografía de Ricardo Palma. En: Revista de la Facultad de Leguas Modernas. № 4. pp. 7-92. Lima: Universidad Ricardo Palma

Ortega, J. (1996) Las Tradiciones peruanas y el proceso cultural del XIX hispanoamericano. Tradiciones Peruanas. Julio Ortega y Flor María Rodríguez- Arenas (Eds.). París: Signatarios Acuerdo Archivos ALCA XX.

Varillas Montenegro, A. (2016) El Demonio de los Andes, pág. xlix. Lima: Academia Peruana de la Lengua.

Recibido: 25 de noviembre del 2017 Aceptado: 15 de enero del 2018 